\title{
Evaluation of Efficacy of the Smear Layer Removal and Micro Hardness of Root Dentin after using Different I rrigants - An In Vitro Study
}

Sangeetha Vallikanthan르, Sainath Dinapadu², Swathi Aravelli³, Aliveni Manga ${ }^{4}$, Sujayeendranath Reddy ${ }^{5}$, Sindhura Reddy ${ }^{6}$

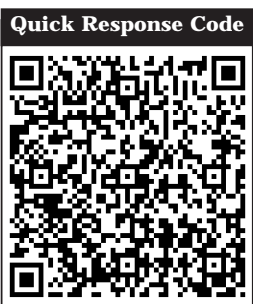

\section{doi: 10.5866/2014.621516}

1,3,4\&6 Senior Lecturer,

2\&5Reader,

Department of Conservative Dentistry and Endodontics, SVS Institute of Dental Sciences,

Mahabubnagar,

Telangana, INDIA.

\section{Article Info:}

Received: J anuary 13, 2014

Review Completed: February 10, 2014

Accepted: March 11, 2014

Available Online: J uly, 2014 (www.nacd.in)

(c) NAD, 2014 - All rights reserved

\section{Email for correspondence:}

Sainathreddy47@gmail.com

\section{ABSTRACT:}

Aim: To evaluate the efficacy of thesmear layer removal and micro hardness of root dentin after using different irrigants. Materials and methods: Sixty freshly extracted single rooted premolars were selected. Root canal preparation is done using ProTaper Rotary instruments. Theteeth were randomly divided into six groups with 10 specimens each and final irrigation of $5 \mathrm{ml}$ each was done as per the groups. The teeth were sectioned longitudinally into two equal halves along the long axis using a hard tissue microtome machine. The one half of the specimen is used for the SEM evaluation and the other one half with the acrylic block is used for the micro hardness study. The data was analysed using Kruskel Wallis One - way ANOVA followed by Mann - Whitney $U$ - test, $p$ $<0.05$ was considered as the level of significance. Results: The best result for the smear layer removal was observed in Group II MTAD $(0.2 \pm 0.4)$, followed by Group VI $5.2 \% \mathrm{NaOCl}+17 \%$ EDTA $(0.3 \pm 0.7)$, Group IV SAEW (0.5 \pm 0.7$)$, Group III $17 \%$ EDTA ( $0.8 \pm$ $0.5)$ and Group I $2.6 \% \mathrm{NaOCl}(1.8 \pm 0.6)$. Dentin Microhardness in Group I (67.42 \pm 10.9$)$, Group II (67.0 \pm 7.8$)$ and in Group V (67.4 \pm 3.4 ) showed significantly higher when compared to the mean values in Group III $(59.7 \pm 4.3)$ and in Group VI $(58.3 \pm 5.0)$ with $p$ $<0.05$. Conclusion: Strong Acid Electrolytic Water had removed the smear layer, but has reduced the microhardness. But MTAD solution effectively removed the smear layer without significantly altering the microhardness of the root dentin.

Key words: chelation, dentine, irrigation, smear layer, sodium hypochlorite.

\section{Introduction}

An important objective in root canal treatment is the removal of pulp tissue and dentinal debris from the root canal system. In addition to biomechanical preparation, it is essential to use an irrigant or combination of irrigants. Since, it helps to clean the areas of the root canal system that could not be directly reached by root canal instrumentation. ${ }^{1}$

Subsequent to biomechanical preparation, an amorphous irregular layer known as the "smear layer" is formed on the root canal walls. Smear layer contains inorganic and organic substances that include fragments of odontoblastic process, micro 
organisms and necrotic debris. ${ }^{2}$ The smear layer consists of a superficial layer on the surface of the canal wall approximately 1 to $2 \mu \mathrm{m}$ in thickness and a deeper layer packed into the dentinal tubules to a depth of $40 \mu \mathrm{m} .^{3}$ The presence of smear layer prevents the penetration of the intra canal medication into theirregularities of the complex root canal system and also prevents the complete adaptation of obturation material to the prepared root canal surface. ${ }^{4}$

Ethylene diamine tetra acetic acid (EDTA) is often suggested as an irrigating solution because it can chelate and remove the mineralized portion of smear layer. It also can decal cify up to a $50 \mu$ m layer of the root canal wall if used liberally. 17\% EDTA is normally used to remove smear layer in less than 1 min if the fluid is able to reach the surface of the root canal wall.

The most common organism, which is being isolated particularly in reinfected root canals, is Enterococcus faecalis. The irrigating solutions like $\mathrm{NaOCl}$ and EDTA helps in eradicating the micro organisms commonly found in the infected root canals effectively.

Various investigators have demonstrated that MTAD also has an ability to remove the smear layer, disinfect contaminated root canals, and found to be effective in eradicating Enterococcus faecalis. MTAD, a new irrigating solution, comprised of a Mixture of Tetracycline isomer, Acid and Detergent has shown promising results. It was reported that the cleanest canals were obtained when $\mathrm{NaOCl}$ was used before a final irrigation and flushing with MTAD. ${ }^{5}$

Recently Strong acid el ectrolytic water (SAEW), also called as "Electrochemically activated water" or "Oxidative potential water" was used extensively in J apan for disinfecting purpose for its safety and antibacterial effect. Since 1996, it has been tried as a root canal irrigant and was reported that, Strong acid electrolytic water could reduce bacteria and remove the smear layer. ${ }^{6}$

The use of the irrigating agents influences the dentin structure and change in the dentin properties. Calcium ions present in hydroxyapatite crystals are one of the main inorganic elements of dentin. Any change in the calcium ion ratio may change the original proportion of the organic and inorganic components. This in turn affects the micro hardness, permeability and solubility characteristics of dentin, sealing ability and adhesion of dental materials such as resin-based cements and root canal sealers to dentin. ${ }^{7}$ It has been further established that removal of the smear layer will enhance the adhesion of root canal sealers to the surface of dentin walls.

Therefore, the present study has been undertaken to evaluate the effectiveness of removal of smear layer and its effect on the micro-hardness of the root dentin after using different irrigants during endodontic procedure.

\section{Materials and Methods}

Sixty single rooted freshly extracted premolars for the orthodontic and periodontic purpose were used for the study. It was stored in normal physiological saline at room temperature. The soft tissue covering the root surface was removed using gauze piece and a fine brush. Later, the teeth were decoronated at the cemento-enamel junction using a diamond disc. Barbed broach (size 20) was used to remove the pulp tissue. A size 10 no $K$ file was introduced into the canal until its tip appeared at the apical foramen. The working length was established by subtracting $1 \mathrm{~mm}$ from this measurement.

Root canal enlargement and preparation was performed by crown down techniqueusing ProTaper Rotary instruments to a size of file F $2.1 \mathrm{ml}$ of saline was used between each file size. The teeth werethen randomly divided into six groups with ten specimens in each, a final irrigation of $5 \mathrm{ml}$ each was done as per the groups.

The treatment groups namely:

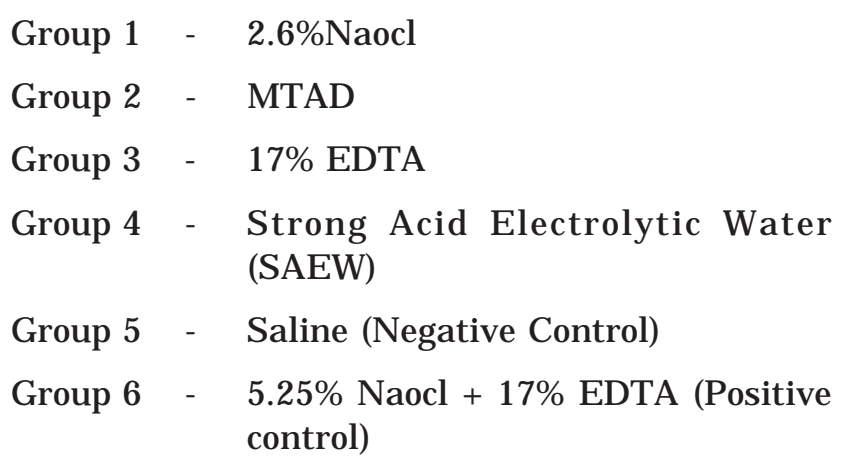




\section{Microtome Sectioning}

After complete irrigation, the teeth were mounted on an acrylic block and sectioned longitudinally into two equal halves along the long axis using a hard tissue microtome machine. The one half of the specimen is used for the SEM evaluation and the other one half with the acrylic block is used for the micro hardness study.

\section{Surface of Root Canal Dentin - SEM Observation}

The one half of the specimens was dried, mounted on metallic stubs and gold sputtered and studied under a scanning electron microscope at magnification of $2000 \times$ at the middle third of the root canal. The amount of debris and the smear layer present was scored (Table 1 ) and frequencies of the scores were subjected to statistical evaluation.

\section{Root Canal Dentin Micro-Hardness}

The other half of the section with acrylic block was taken and $3 \mathrm{~mm}$ sectioning was done. These specimens were divided into 6 groups, immersed in $20 \mathrm{ml}$ of the respective irrigating solution for duration of 5 minutes. Later the section was subjected to Vicker's micro hardness testing. $\mathrm{H}$ ardness was measured under the condition of load 50 grams and a retentive duration of 15 seconds in five dentin areas on the middle third of the root canal of each specimen and the mean average of the five indentations was taken and the results were statistically evaluated.

\section{Statistical Analysis}

Mean and standard deviation were estimated from the samples from each study group. Mean values were compared among different study groups by using K ruskel-Wallis, One-way ANOVA followed by Mann - Whitney $U$ test. Kolmogrov-Smirnov test was used to test the normality of the data in each study group. Pearson's chi-square test was used to assess the relationship between SEM scores and different study groups. In the present study, $\mathrm{p}<0.05$ was considered as the level of significance.

\section{Results}

Among the Groups observed under the scanning electron microscope, Group II, IV and VI smear layer was removed successfully. The best result for the smear layer removal was observed in Group II MTAD $(0.2 \pm 0.4)$, followed by Group VI $5.2 \% \mathrm{NaOCl}$ $+17 \%$ EDTA (0.3 \pm 0.7$)$, Group IV SAEW (0.5 \pm 0.7$)$, Group III 17\% EDTA (0.8 \pm 0.5$)$ and Group I 2.6\% $\mathrm{NaOCl}(1.8 \pm 0.6)$. For the smear scores the significance level was $p<0.001$. (Table 2 )

The mean debris removal was best observed in Group II MTAD (0.2 \pm 0.4$)$, then Group VI 5.2\% $\mathrm{NaOCl}+17 \%$ EDTA $(0.4 \pm 0.5)$, Group IV SAEW (0.6 \pm 0.8 ) followed by Group III 17\% EDTA (0.9 \pm 0.4 ) and Group I $2.6 \% \mathrm{NaOCl}(1.8 \pm 0.6)$. (Table 3)

Dentin Microhardness in Group I (67.42 \pm 10.9$)$, Group II (67.0 \pm 7.8$)$ and in Group V (67.4 \pm 3.4$)$ showed significantly higher when compared to the mean values in Group III (59.7 \pm 4.3$)$ and Group VI $(58.3 \pm 5.0)$ with $p<0.05$. F urther the mean of Dentin Microhardness (VHN) in Group V $(67.4 \pm 3.4)$ is significantly lower than the Group IV $(60.6 \pm 9.9)$ with $\mathrm{p}<0.05$. (Table 4)

\section{Discussion}

Cleaning and shaping of the root canal system are considered the key requirements for success in root canal treatment. ${ }^{8}$ I rrigation of root canal system provides gross debridement, Iubrication and destruction of microbes and dissolution of tissues. ${ }^{9}$ Further they help in cleaning those areas that are inaccessible for mechanical cleansing. ${ }^{3}$ During canal preparation dentinal debris created by the action of endodontic instrumentation and remnants of organic matter, forming a smear layer, may adheres to the canal walls. ${ }^{10}$

This layer can form two zones; the first zone is superficial zone which is made up of $1-2 \mu \mathrm{m}$ of organic matter and dentin particles; the second layer is deeper zone which extends into the dentinal tubules to a depth of $40 \mu \mathrm{m} .{ }^{10}$ Removal of the smear layer requires the use of irrigants that can dissolve both the organic and inorganic components. ${ }^{7}$ Acid solutions have been recommended for removing the smear layer.

The decalcifying efficacy of these acids and chelating agents depends on the root length, duration of application time, diffusion in the dentin and the $\mathrm{pH}$ of the solution. ${ }^{11}$

In the present study, Group I - $2.6 \%$ sodium hypochlorite was used as the irrigant. It was not capable of removing the smear layer that remained 


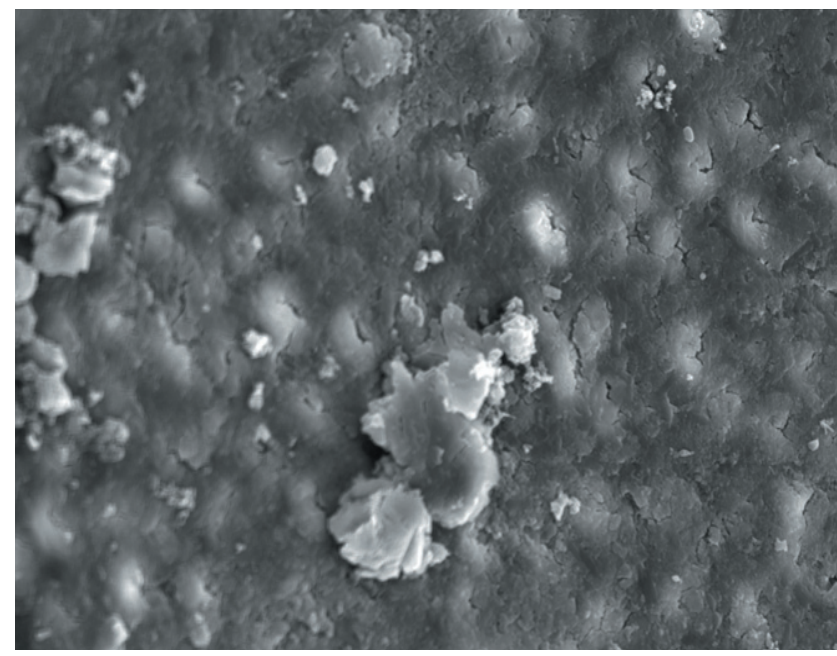

Figure 1: SEM photomicrographs of Group I

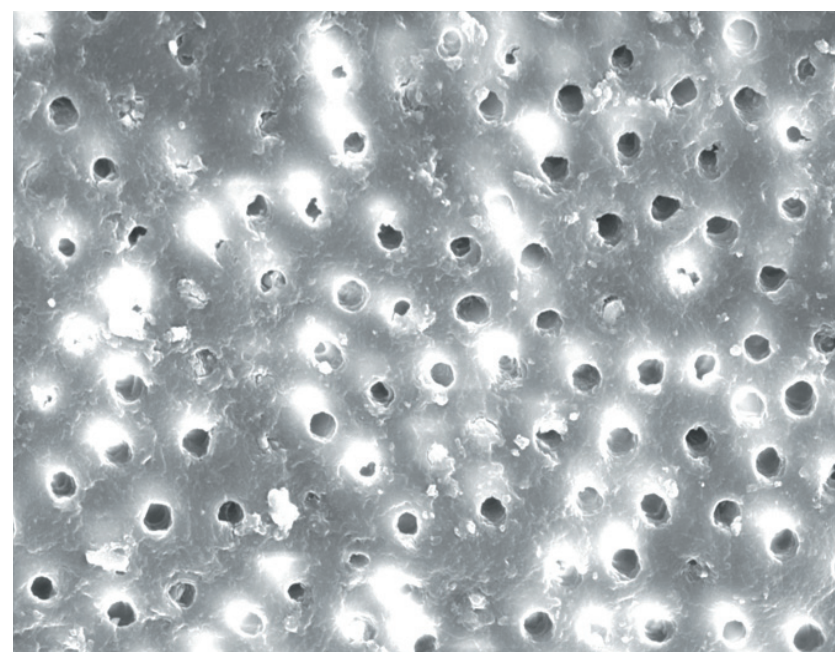

Figure 3: SEM photomicrographs of Group III

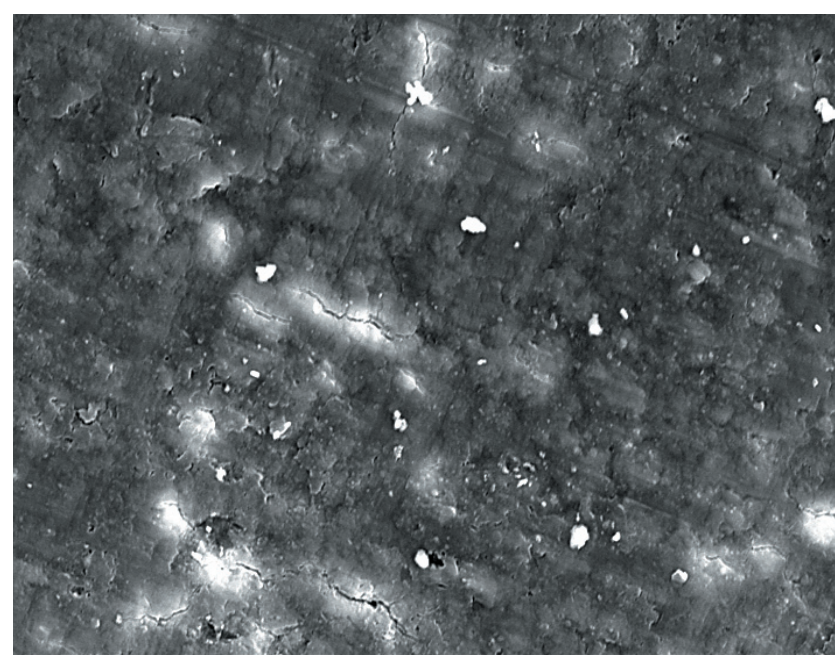

Figure 5: SEM photomicrographs of Group V

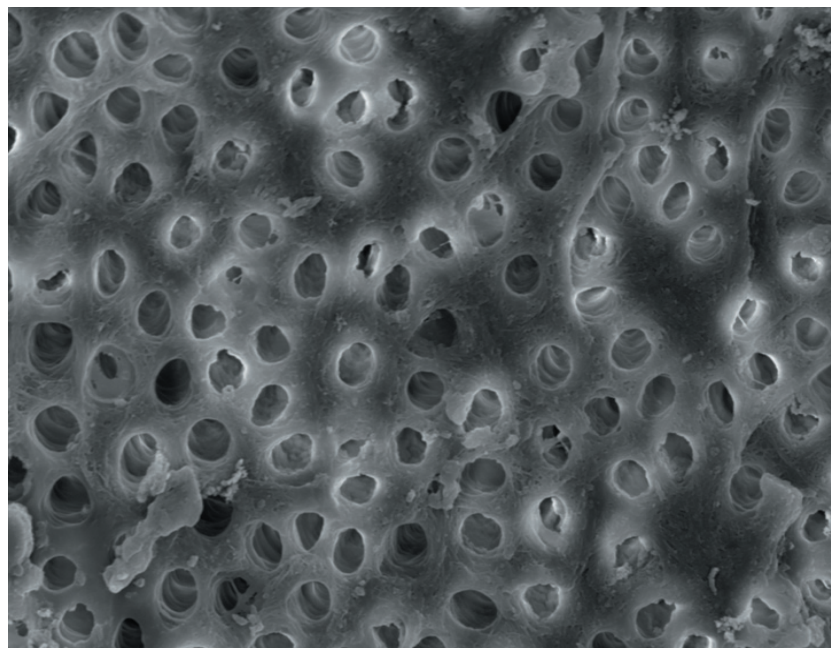

Figure 2: SEM photomicrographs of Group II

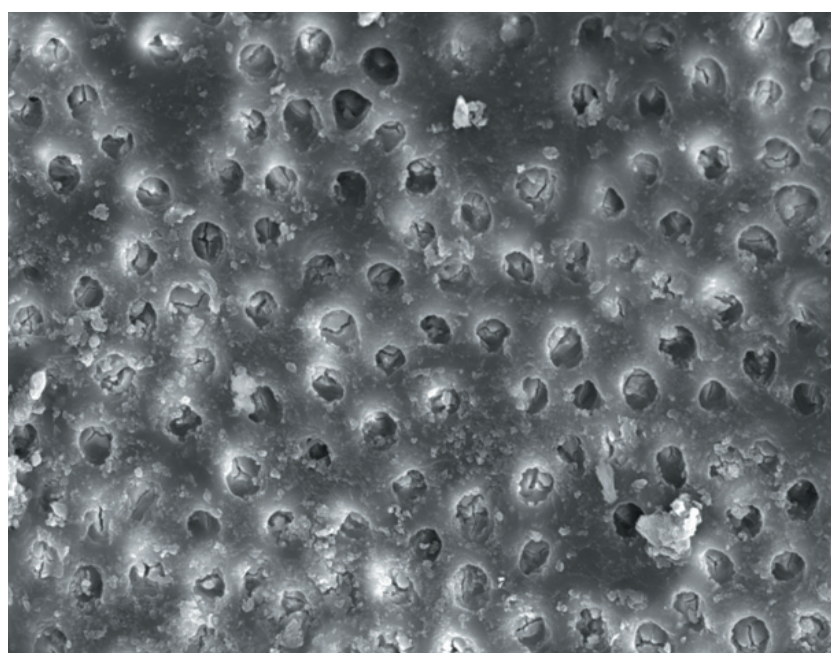

Figure 4: SEM photomicrographs of Group IV

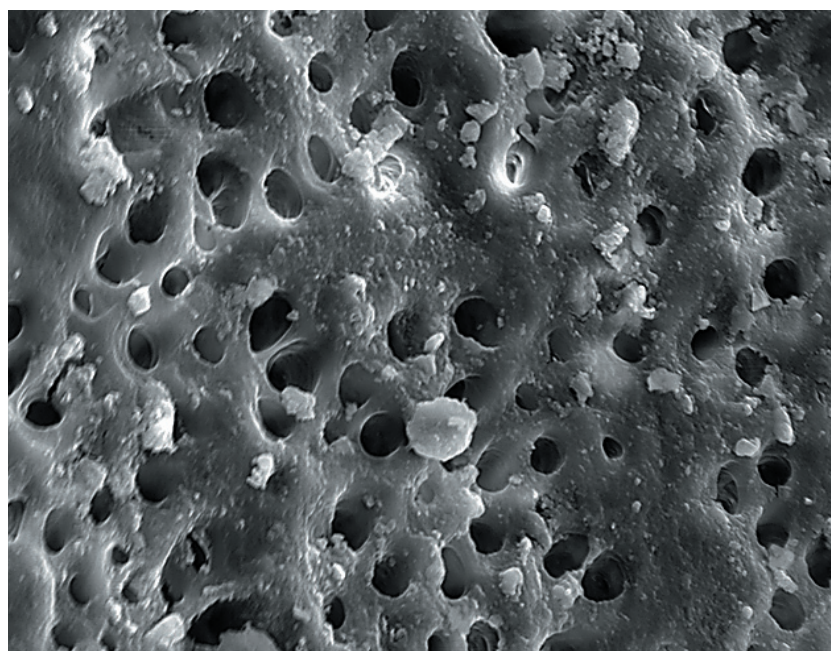

Figure 6: SEM photomicrographs of Group VI 
Table 1: Smear and Debris scoring

\begin{tabular}{cl}
$\begin{array}{c}\text { Score } \\
\text { Smear score }\end{array}$ & Observation \\
\hline 0 & All the dentinal tubules are open and no smear layer present \\
\hline 1 & $\begin{array}{l}\text { Some dentinal tubules are open with smear layer covering some of the openings of } \\
\text { the dentinal tubules }\end{array}$ \\
\hline 2 & All the dentinal tubules are covered by smear layer \\
\hline 0 & No debris present \\
\hline 1 & Few debris particles present \\
\hline 2 & Large amount of debris present \\
\hline
\end{tabular}

Table 2: Mean of smear layer scores

\begin{tabular}{|c|c|c|c|c|}
\hline Group & $\begin{array}{l}\text { Endodontic Irrigating } \\
\text { solution }\end{array}$ & Mean \pm SD & P - value & $\begin{array}{l}\text { Significant groups } \\
\text { at } 5 \% \text { level }\end{array}$ \\
\hline Group I & $2.6 \% \mathrm{NaOCl}$ & $1.8 \pm 0.6$ & & I vs II, IV, VI \\
\hline Group II & MTAD & $0.2 \pm 0.4$ & & V vs II , IV, VI \\
\hline Group III & 17\% EDTA & $0.8 \pm 0.5$ & $<0.0001$ & III vs II, IV, VI \\
\hline Group IV & SAEW & $0.5 \pm 0.7$ & & \\
\hline Group V & Saline & $2.0 \pm 0.0$ & & \\
\hline Group VI & $5.26 \% \mathrm{NaOCI}+17 \%$ EDTA & $0.3 \pm 0.5$ & & \\
\hline
\end{tabular}

Table 3: Mean of debris scores

\begin{tabular}{lllll} 
Group & $\begin{array}{l}\text { Endodontic Irrigating } \\
\text { solution }\end{array}$ & Mean \pm SD & P - value & $\begin{array}{l}\text { Significant groups } \\
\text { at 5\% level }\end{array}$ \\
Group I & $2.6 \% \mathrm{NaOCI}$ & $1.8 \pm 0.6$ & & I VS II, IV, VI \\
Group II & MTAD & $0.2 \pm 0.4$ & & V vs II, IV, VI \\
Group III & $17 \%$ EDTA & $0.9 \pm 0.4$ & $<0.0001$ & III vs II, IV, VI \\
Group IV & SAEW & $0.6 \pm 0.8$ & & \\
Group V & Saline & $2.0 \pm 0.0$ & & \\
Group VI & $5.26 \% \mathrm{NaOCI}+17 \%$ EDTA & $0.4 \pm 0.5$ & & \\
\hline
\end{tabular}

Table 4: Mean of microhardness of root dentin

\begin{tabular}{|c|c|c|c|c|c|}
\hline Group & $\begin{array}{l}\text { Endodontic } \\
\text { Irrigating } \\
\text { solution }\end{array}$ & $\mathbf{N}$ & $\begin{array}{l}\text { Vickers } \\
\text { Microhardness } \\
\text { values (Mean } \pm \text { SD) }\end{array}$ & $\begin{array}{l}\text { Overall } \\
\text { P - value* }\end{array}$ & $\begin{array}{l}\text { Significant } \\
\text { groups } \\
\text { at } 5 \% \text { level** }\end{array}$ \\
\hline Group I & $2.6 \% \mathrm{NaOCl}$ & 10 & $67.2 \pm 10.9$ & 0.002 & VI vs I,II,V \\
\hline Group II & MTAD & 10 & $67.0 \pm 7.8$ & (Significance) & IV vs V \\
\hline Group III & 17\% EDTA & 10 & $59.7 \pm 4.3$ & & III vs I,II, V \\
\hline Group IV & SEAW & 10 & $60.6 \pm 9.9$ & & \\
\hline Group V & Saline & 10 & $67.4 \pm 3.4$ & & \\
\hline Group VI & $\begin{array}{l}5.26 \% \mathrm{NaOCl} \\
.+17 \% \mathrm{EDTA}\end{array}$ & 10 & $58.3 \pm 5.0$ & & \\
\hline
\end{tabular}


attached to the dentinal walls of the root canal. The limitations of its action may be due to its in-ability to remove the smear layer and incomplete action against bacteria due to resistance against some strains (Figure 1 ). This observation is in accordance with D M Z Guerisoli et al, who also observed that sodium hypochlorite alone did not clean the smear layer better than distilled water.

Torabinejad et al developed a new solution, called BioPure MTAD, comprises of an aqueous solution of $3 \%$ doxycycline, $4.25 \%$ citric acid and $0.5 \%$ polysorbate 80 detergent. They observed that BioP ure MTAD simultaneously removed the smear layer and disinfect the root canal system. It has been reported that the cleanest canals were obtained when sodium hypochlorite was used prior to MTAD as a final rinse. ${ }^{7,12}$

In Group II, specimens treated with where MTAD used as a final irrigant, performed better and effectively removed the smear layer when compared to saline, $17 \%$ EDTA, $2.6 \% \mathrm{NaOCI}$ and SAEW. Smear layer was completely removed and the marginal outline of the dentinal tubule orifice is clear (Figure 2). From this one can draw to the conclusion that MTAD does not significantly affect the structure of dentinal tubules when used as a final irrigant in conjunction with low concentration of sodium hypochlorite.

MTAD when used subsequent to irrigation with $1.3 \%$ sodium hypochlorite removes smear layer in various parts of the root canal without causing erosion of the dentin. The presence of $4.5 \%$ citric acid helps in the removal of the smear layer, 3\% doxycycline helps in eliminating microbes that are resistant to conventional endodontic irrigants, providing sustained antimicrobial activity. The presence of detergent Tween 80 has the ability to enhance the penetration of the medicament into the dentinal tubules by lowering the surface tension.

In Group III, 17\% EDTA as an irrigant was used. It was observed that smear layer on the root canal walls, was not completely removed. But the dentin surface appeared smooth, not eroded and dentinal tubule orifices were regular and separated (Figure 3).

It was reported that root canal irrigation with $15 \%$ EDTA resulted not only in removal of the smear layer, but also in demineralization of dentin immediately below the smear layer, thereby reducing its hardness. Reducing the concentration of EDTA can prevent this excessive demineralization. However, the removal of the smear layer was difficult with EDTA solution at a low concentration since it releases hydrogen ions with the progression of the chelation reaction, leading to an acidic environment where chelation is minimized. ${ }^{13}$ EDTA acts upon the inorganic components of smear layer, causes the decalcification of peritubular and intertubular dentin and leaves the collagen exposed.

In Group IV, Strong Acid E lectrolytic Water was used as the irrigating solution, the Smear layer on the root canal walls were completely removed after the final irrigation. But the marginal outline of the dentinal tubule does not appear to be clear and is very irregular (Figure 4). Strong Acid Electrolytic Water has been developed in J apan and claims to have an outstanding antimicrobial activity, which destroys bacteria and viruses also. ${ }^{14}$

It has an advantage over sodium hypochlorite and EDTA because it has comparatively low toxicity, less irritant to soft tissues and reacts with organic substances.

In group V, Saline was used as a control in the study. This group showed no effect on the smear layer and debris removal. Infact smear layer is observed on the entire wall of the root canal in all the specimens (Figure 5).

Sim et al and Driscoll et al reported that irrigation of the root canal system with water or saline does not alter the mechanical and chemical properties of root canal dentine. ${ }^{15}$

In Group VI, the positive control group is the combination of $5.2 \% \mathrm{NaOCl}$ and $17 \%$ EDTA as a final irrigant for the root canals. Yamada et al in 1983 recommended the use of EDTA with $\mathrm{NaOCl}$ solutions for effective removal of the smear layer from the surface of the root canal walls. The association of EDTA and $\mathrm{NaOCl}$ solutions proved effective in removing thesmear layer formed during endodontic instrumentation. After the final irrigation, the dentin surface was rough in appearance and dentinal tubule orifices were irregularly enlarged due to decalcification of the 
inorganic component by EDTA and dissolution of the organic matrix by $\mathrm{NaOCl}$ (Figure 6).

Ayce Unverdi Eldeniz et al claimed that irrigation of the root canals with EDTA and $\mathrm{NaOCl}$ solutions reduced the micro hardness and increased the roughness of root canal dentin. In the present study also $5.25 \%$ of $\mathrm{NaOCl}$ and $17 \%$ EDTA was found to be effective in reducing the micro hardness of root dentin.

Based on the results of this investigation we can conclude that use of $5.25 \%$ of $\mathrm{NaOCl}$ along with EDTA was found to be more effective in reducing the micro hardness of root dentin. Whereas, $2.6 \%$ $\mathrm{NaOCl}$ has showed minimal effect on reducing the dentin microhardness, but was not effective in removing the smear layer.

Strong Acid Electrolytic Water had removed the smear layer, but reduced the microhardness whereas MTAD removed the smear layer completely, without affecting the dentin microhardness. Hence use of MTAD as an irrigating solution has a better scope in clinical situations.

\section{Conclusion:}

Canal irrigation with these chemical solutions lead to structural changes as evidenced by reduction of the microhardness of root dentin along with the removal of the smear layer. From this study it is evident that MTAD can be considered an ideal irrigating solution in removing the smear layer as well as to preservethemicro hardness of root dentin.

\section{Acknowledgments}

We would like to thank I.I.T. Chennai and Annamalai University (Physics Department) for guiding us and allowing us to use their department facility to conduct our experiment. We would also like to thank Saveetha Dental College, Chennai for constantly guiding us and supporting us throughout this research.

\section{References}

1. Marending M, Paque F, Fischer J, Zehnder M Impact of irrigant sequence on mechanical properties of human root dentin. J Endod. 2007; 33(11):1325-1328.

2. Lui JN, Kuah HG, Chen NNJ Effect of EDTA with and without surfactants or ultrasonics on removal of smear layer. J Endod. 2007; 33(4):472-475.
3. Torabinejad M, Handysides R, Khademi AA, Bakland LK Clinical implications of the Smear layer in endodontics, Oral Surg Oral Med Oral Pathol Oral Radiol Endod. 2002; 94(6):658-666.

4. Torabinejad M, Khademi AA, Babagoli J, Cho Y, J ohnson WB, Bozhilov K, Kim J, Shabahang S A New Solution for the Removal of the Smear layer, J Endod, 2003; 29(3); 170175.

5. J ohal S, Baumgartner J C, Marshall J G. Comparison of the Antimicrobial Efficacy of $1.3 \% \mathrm{NaOCl} / \mathrm{BioP}$ ure MTAD to $5.25 \% \mathrm{NaOCI} / 15 \%$ EDTA for Root Canal I rrigation, J Endod 2007; 33(1):48-51.

6. Qing Y, Akita Y, Kawano S, Kawazu S, Yoshida T, Sekine I Cleaning Efficacy and Dentin Microhardness After Root Canal Irrigation with a Strong Acid Electrolytic water, J Endod 2006; 32(11):1102-1106.

7. Tay FR, Pashley DH, Loushine RJ, Doyle MD, GillespieWT, Weller RN, King NM Ultrastructure of smear layer-covered intraradicular Dentin After I rrigation with BioPure MTAD. J Endod 2006; 32(2):18-221.

8. Perez-Heredia M, Ferrer-Luque CM, González-Rodríguez MP. The Effectiveness of Different Acid I rrigating Solutions in Root Canal Cleaning After $\mathrm{Hand}$ and Rotary Instrumentation. J Endod 2006; 32(10):993 - 997.

9. Ari H, Erdemir A, Belli S Evaluation of the Effect of Endodontic Irrigation Solution on the Microhardness and the Roughness of Root canal Dentin. J Endod 2004; 30(11):792 - 795.

10. Teixeira CS, Felippe MC, Felippe WT The Effect of application of EDTA and $\mathrm{NaOCl}$ on intracanal smear layer removal: an SEM analysis. Int Endod J 2005; 38(5):285290.

11. Perez-Heredia M, Ferrer-Luque CM, Gonzalez-Rodriguez MP, Martin-Peinado FJ , Gonzalez-Lopez S. Decalcifying effect of $15 \%$ EDTA, 15\% citric acid, 5\% phosphoric acid and $2.5 \%$ sodium hypochlorite on root canal dentine. Int Endod J 2008; 41(5):418 - 423.

12. Machnick TK, Torabinejad M, Munoz CA, Shabahang S. Effect of MTAD on Flexural Strength and Modulus of Elasticity of Dentin, J Endod 2003; 29(11):747-750.

13 Nakashima K, Terata R. Effect of Ph Modified EDTA Solution to the Properties of Dentin. J Endod 2005; 31(1): 47-50.

14. Gulabivala K, Stock CJ , Lewsey J D, Ghori S, Ng YL, Spratt DA. Effectiveness of electrochemically activated water as an irrigant in an infected tooth model. Int Endod J 2003; 36:810 - 830.

15. Dogan Buzoglu H, Calt S, Gümüsderelioglu M Evaluation of the surface free energy on canal dentine walls treated with chelating agents and $\mathrm{NaOCl}$. Int Endod J 2007; 40 (1):18 - 24 . 